\title{
Usefulness of Extracorporeal Shockwave Therapy on Myofascial Pain Syndrome
}

\author{
Chang Han Lee, $\mathrm{MD}^{1}$, Shi-Uk Lee, MD, $\mathrm{PhD}^{2}$
}

\author{
${ }^{1}$ Department of Rehabilitation Medicine, Gyeongsang National University School of Medicine, \\ Gyeongsang National University Hospital, Jinju; \\ ${ }^{2}$ Department of Rehabilitation Medicine, Seoul National University College of Medicine, \\ SMG-SNU Boramae Medical Center, Seoul, Korea
}

Myofascial pain syndrome (MPS) is a clinically common observation with characteristics such as localized muscle tenderness, a palpable intramuscular taut band, and muscle spasm following trigger point injection [1]. It is a musculoskeletal disorder with sensory, motor, and autonomic symptoms and is commonly encountered in clinical settings [2]. Myofascial trigger points (MTrPs) are the primary cause of MPS, accounting for approximately $54 \%$ of chronic pain in the head and neck [3]. A recent study also found that the upper trapezius muscles were the primary cause of MPS in patients with chronic nonspecific neck pain [4].

The exact pathophysiology of MTrPs and MPS remains unknown. However, the proposed mechanisms have been reported in the literature. MPS is thought to be a complex form of neuromuscular dysfunction consisting of motor and sensory abnormalities involving peripheral and central nervous systems $[5,6]$. The primary mechanism is known to involve an abnormal increase in acetylcholine, triggering a continuous release and uptake of calcium ions, leading to muscle ischemia resulting from a sustained shortening of sarcomeres and release of sensitizing substances $[7,8]$. Excessive release of acetylcholine may cause the development of a tight band that results in persistent muscle contraction [9].

There are various therapeutic approaches to treat MPS, including invasive techniques (such as dry needling, trigger point injection) and non-invasive techniques (such as drug therapy and electrical and exercise treatments). Electrical treatments include interference current therapy, ultrasound, and transcutaneous electrical nerve stimulation, while exercise treatments include stretching, massage, and taping [10-13].

As a non-invasive and safe modality, the use of extracorporeal shock wave therapy (ESWT) has expanded to the treatment of MPS [12,14-17]. Some evidence-based medical reviews have also explored the effectiveness of ESWT for MPS of the trapezius muscle [18-20]. ESWT improves capillary blood circulation in ischemic zones and alters pain signaling in ischemic tissues caused by calcium influx in a study by De Sanctis et al. [21]. A previous study demonstrated that ESWT might interrupt the cascade of referred pain by inhibiting peripheral muscle nociceptors and reducing the levels of substance $\mathrm{P}[15]$.

However, thus far, not a single treatment modality has been proven to be superior to treat MPS. A systematic review and meta-analysis suggested ESWT to be helpful for pain in patients with MPS of the trapezius and could

Received July 5, 2021; Accepted July 7, 2021; Published online August 30, 2021

Corresponding author: Shi-Uk Lee

Department of Rehabilitation Medicine, Seoul National University College of Medicine, SMG-SNU Boramae Medical Center, 20 Boramae-ro 5-gil, Dongjak-gu, Seoul 07061, Korea. Tel: +82-2-870-2671, Fax:+82-2-870-3866, E-mail: shiuk.lee@gmail.com

ORCID: Chang Han Lee (https://orcid.org/0000-0001-8351-5226); Shi-Uk Lee (https://orcid.org/0000-0003-0850-5217).

(c) This is an open-access article distributed under the terms of the Creative Commons Attribution Non-Commercial License (http://creativecommons.org/ licenses/by-nc/4.0) which permits unrestricted noncommercial use, distribution, and reproduction in any medium, provided the original work is properly cited. Copyright $\odot 2021$ by Korean Academy of Rehabilitation Medicine 
serve as an adjunct therapeutic method to treatments such as dry needling, trigger point injection, and laser therapy [19]. In light of these observations, a study on the impact of the combined effect of ESWT and integrated neuromuscular inhibition on MPS of the upper trapezius published in this issue of the Annals of Rehabilitation Medicine can be considered highly remarkable [22]. The authors investigated the combined effect of ESWT and integrated neuromuscular inhibition on MPS of the upper trapezius in 60 subjects aged 18-24 years by randomized controlled trials. The results revealed that the combined treatment of ESWT and integrated neuromuscular inhibition for treating MTrPs in the upper trapezius is more effective than using only one of them considering the clinical, functional, and neurophysiological aspects.

ESWT should be recommended as a standard therapy in clinical settings for managing MPS of the upper trapezius. Considering various mechanisms of MPS, combined therapy with ESWT and other interventions would be a reliable treatment method for MPS of the upper trapezius.

\section{CONFLICT OF INTEREST}

No potential conflict of interest relevant to this article was reported.

\section{AUTHOR CONTRIBUTION}

Conceptualization: Lee SU. Methodology: Lee SU, Lee $\mathrm{CH}$. Writing - original draft: Lee CH. Writing - review and editing: Lee SU. Approval of final manuscript: all authors.

\section{REFERENCES}

1. Sciotti VM, Mittak VL, DiMarco L, Ford LM, Plezbert J, Santipadri E, et al. Clinical precision of myofascial trigger point location in the trapezius muscle. Pain 2001;93:259-66.

2. Borg-Stein J, Simons DG. Focused review: myofascial pain. Arch Phys Med Rehabil 2002;83(3 Suppl 1):S407.

3. Rachlin ES, Rachlin IS. Myofascial pain and fibromyalgia. 2nd ed. St. Louis, MO: Mosby; 2002.

4. Cerezo-Tellez E, Torres-Lacomba M, Mayoral-Del Moral O, Sanchez-Sanchez B, Dommerholt J, Gutier-
rez-Ortega C. Prevalence of myofascial pain syndrome in chronic non-specific neck pain: a populationbased cross-sectional descriptive study. Pain Med 2016;17:2369-77.

5. Shah JP, Danoff JV, Desai MJ, Parikh S, Nakamura LY, Phillips TM, et al. Biochemicals associated with pain and inflammation are elevated in sites near to and remote from active myofascial trigger points. Arch Phys Med Rehabil 2008;89:16-23.

6. Kuan TS, Hong CZ, Chen JT, Chen SM, Chien CH. The spinal cord connections of the myofascial trigger spots. Eur J Pain 2007;11:624-34.

7. Ottomann C, Hartmann B, Tyler J, Maier H, Thiele R, Schaden W, et al. Prospective randomized trial of accelerated re-epithelization of skin graft donor sites using extracorporeal shock wave therapy. J Am Coll Surg 2010;211:361-7.

8. Shah JP, Gilliams EA. Uncovering the biochemical milieu of myofascial trigger points using in vivo microdialysis: an application of muscle pain concepts to myofascial pain syndrome. J Bodyw Mov Ther 2008;12:371-84.

9. Hong CZ, Simons DG. Pathophysiologic and electrophysiologic mechanisms of myofascial trigger points. Arch Phys Med Rehabil 1998;79:863-72.

10. Tough EA, White AR, Cummings TM, Richards SH, Campbell JL. Acupuncture and dry needling in the management of myofascial trigger point pain: a systematic review and meta-analysis of randomised controlled trials. Eur J Pain 2009;13:3-10.

11. Rickards LD. The effectiveness of non-invasive treatments for active myofascial trigger point pain: a systematic review of the literature. Int J Osteopath Med 2006;9:120-36.

12. Muller-Ehrenberg H, Licht, G. Diagnosis and therapy of myofascial pain syndrome with focused shock waves (ESWT). Med Orthop Tech 2005;5:1-6.

13. de las Penas CF, Campo MS, Carnero JF, Page JC. Manual therapies in myofascial trigger point treatment: a systematic review. J Bodyw Mov Ther 2005;9:27-34.

14. Jeon JH, Jung YJ, Lee JY, Choi JS, Mun JH, Park WY, et al. The effect of extracorporeal shock wave therapy on myofascial pain syndrome. Ann Rehabil Med 2012;36:665-74.

15. Ji HM, Kim HJ, Han SJ. Extracorporeal shock wave therapy in myofascial pain syndrome of upper trape- 
zius. Ann Rehabil Med 2012;36:675-80.

16. Cho YS, Park SJ, Jang SH, Choi YC, Lee JH, Kim JS. Effects of the combined treatment of extracorporeal shock wave therapy (ESWT) and stabilization exercises on pain and functions of patients with myofascial pain syndrome. J Phys Ther Sci 2012;24:1319-23.

17. Gur A, Koca I, Karagullu H, Altindag O, Madenci E. Comparison of the efficacy of ultrasound and extracorporeal shock wave therapies in patients with myofascial pain syndrome: a randomized controlled study. J Musculoskelet Pain 2013;21:210-6.

18. Yoo JI, Oh MK, Chun SW, Lee SU, Lee CH. The effect of focused extracorporeal shock wave therapy on myofascial pain syndrome of trapezius: a systematic review and meta-analysis. Medicine (Baltimore) 2020;99:e19085.

19. Zhang Q, Fu C, Huang L, Xiong F, Peng L, Liang Z, et al. Efficacy of extracorporeal shockwave therapy on pain and function in myofascial pain syndrome of the trapezius: a systematic review and meta-analysis. Arch Phys Med Rehabil 2020;101:1437-46.

20. Jun JH, Park GY, Chae CS, Suh DC. The Effect of Extracorporeal shock wave therapy on pain intensity and neck disability for patients with myofascial pain syndrome in the neck and shoulder: a meta-analysis of randomized controlled trials. Am J Phys Med Rehabil 2021;100:120-9.

21. De Sanctis MT, Belcaro G, Nicolaides AN, Cesarone MR, Incandela L, Marlinghaus E, et al. Effects of shock waves on the microcirculation in critical limb ischemia (CLI) (8-week study). Angiology 2000;51(8 Pt 2):S69-78.

22. Mohamed DA, Kamal RM, Gaber MM, Aneis YM. Combined effect of extracorporeal shockwave therapy and integrated neuromuscular inhibition on myofascial trigger points of upper trapezius: a randomized controlled trial. Ann Rehabil Med 2021;45:284-93. 